\title{
ANALYSIS OF THE TECHNICAL AND ECONOMIC FEASIBILITY OF USING ELECTRIC PROPULSION IN BRAZILIAN NAVY PASSENGER TRANSPORT VESSELS: AN APPROACH OF AHP METHOD
}

\begin{abstract}
The access of students, civil and military servants from the pier of the 1st Naval District to Hoe island (located in Guanabara Bay, Rio de Janeiro/Brazil) occurs through vessels that carry out a daily travel routine, generating considerable fuel consumption. The purpose of this work is to analyze the technical and economic feasibility of implementing electric propulsion by lithium-ion batteries in new vessels, to replace the current ones, which use the conventional diesel system. For this purpose, technical and operational data were collected from these vessels, commercial proposals were requested from companies in the sector, and the Analytic Hierarchy Process (AHP) method was used to assist in the assessment of the main criteria involved. The study verified the feasibility of the project and may serve as a basis in order to promote this technology on other vessels in the various districts of the Brazilian Navy.
\end{abstract}

Keywords: Analytic Hierarchy Process (AHP), Electric propulsion, Lithium ion batteries.

\section{Introduction}

The investment in the development of new technologies in the area of electric propulsion systems for vessels has been intensifying in recent decades. However, the decision to adopt new technologies in place of existing ones should be carried out cautiously, through studies that analyze their impacts in the environment where it will be inserted.

This article aims to analyze through the use of the hierarchical analysis method (AHP) as a multicriteria aid tool in the decision-making process, the technical and economic feasibility of applying the technology of electric propulsion using lithium-ion batteries (LiIon) for energy accumulation in vessels that carry out the transport of passengers from the pier of the 1st Naval District to the Island of the Hoes.

\section{Literature Review}

According to Symington (2016), promising new chemicals for batteries are being developed and existing ones being enhanced with nanotechnology. Shipyard and vessel owners are increasingly investing in hybrid and electric marine systems in order to increase flexibility in the design of new vessels, as well as improving operational performance and management practices to increase their competitive advantage in the face of competition from the foreign market (Mello et al., 2011). 


\section{Hypotheses/Objectives}

The Brazilian Navy's passenger transport vessels of the Admiral Wandenkolk Instruction Center (CIAW) perform daily the transfer of students, civil and military servants. During a pattern routine day, about forty crossings are performed, generating an average monthly consumption of four thousand five hundred liters of Marine Diesel Oil, which is considered a very high consumption, not to mention environmental factors. Our study aims, through the application of the AHP method, to verify the feasibility of the adoption of electric propulsion as an alternative to increasing environmental and economic sustainability.

\section{Research Design/Methodology}

For the study, we analyzed the technical and operating data of two of the five vessels that are currently in operation in the function: CIAW 08 SIRIUS II and CIAW 07 CONOPUS II. These data were obtained through technical manuals, field research and interview with the military personnel responsible for their operation and maintenance. With the data obtained, an analysis was performed with the AHP tool, to verify which propulsion system offers the greatest benefits considering the criteria: Acquisition Cost (C1), Operating Cost (C2), Socio-Environmental aspect (C3) and Total Gross Mass (C4).

\section{Data/Model Analysis}

Based on Saaty (1980), Table 1 presents the preference matrix, obtained through interviews with CIAW military officers.

Table 1 - Evaluation of the criteria considered.

\begin{tabular}{ccccccccccc}
\hline \multicolumn{3}{c}{ Preference between criteria } & \multicolumn{1}{c}{ Normalization } & \multicolumn{2}{c}{ Average } \\
\hline $\mathrm{C} 1$ & 1 & $1 / 3$ & $1 / 7$ & 5 & $\mathrm{C} 1$ & $1 /(56 / 5)$ & $(1 / 3) /(40 / 9)$ & $(1 / 7) / 100 / 63)$ & $5 / 24$ & 0,11565476 \\
$\mathrm{C} 2$ & 2 & 1 & $1 / 3$ & 9 & $\mathrm{C} 2$ & $3 /(56 / 5)$ & $1 /(40 / 9)$ & $(1 / 3) /(100 / 63)$ & $9 / 24$ & 0,26946429 \\
$\mathrm{C} 3$ & 7 & 3 & 1 & 9 & $\mathrm{C} 3$ & $7 /(56 / 5)$ & $3 /(40 / 9)$ & $1 /(100 / 63)$ & $9 / 24$ & 0,57625 \\
$\mathrm{C} 4$ & $1 / 5$ & $1 / 9$ & $1 / 9$ & 1 & $\mathrm{C} 4$ & $(1 / 5) /(56 / 5)$ & $(1 / 9) /(40 / 9)$ & $(1 / 9) /(100 / 63)$ & $1 / 24$ & 0,03863095 \\
\hline$\Sigma$ & $56 / 5$ & $40 / 9$ & $100 / 63$ & 24 & $\Sigma$ & 1 & 1 & 1 & 1 & \\
\hline
\end{tabular}

Analogously, the alternatives considered in the analysis are evaluated (Table 2).

Table 2 - Evaluation of alternatives.

\begin{tabular}{|c|c|c|c|c|c|c|}
\hline \multicolumn{7}{|c|}{ Deployment Cost Criterion } \\
\hline \multicolumn{3}{|c|}{ Preference } & \multicolumn{3}{|c|}{ Normalization } & \multirow[t]{2}{*}{ Average } \\
\hline $\mathrm{C} 1$ & Diesel & Electric & $\mathrm{C} 1$ & Diesel & Electric & \\
\hline Diesel & 1 & 5 & Diesel & $1 /(6 / 5)$ & $5 / 6$ & 0,8333 \\
\hline Electric & $1 / 5$ & 1 & Electric & $(1 / 5) /(6 / 5)$ & $1 / 6$ & 0,1666 \\
\hline$\Sigma$ & $6 / 5$ & 6 & $\Sigma$ & 1 & 1 & \\
\hline \multicolumn{7}{|c|}{ Operating Cost Criterion } \\
\hline \multicolumn{3}{|c|}{ Preference } & \multicolumn{3}{|c|}{ Normalization } & Average \\
\hline $\mathrm{C} 2$ & Diesel & Electric & $\mathrm{C} 2$ & Diesel & Electric & \\
\hline Diesel & 1 & $1 / 5$ & Diesel & $1 / 6$ & $(1 / 5) /(6 / 5)$ & 0,1666 \\
\hline Electric & 5 & 1 & Electric & $5 / 6$ & $1 /(6 / 5)$ & 0,8333 \\
\hline$\Sigma$ & 6 & $6 / 5$ & $\Sigma$ & 1 & 1 & \\
\hline \multicolumn{7}{|c|}{ Socio-environmental Aspect Criterion } \\
\hline \multicolumn{3}{|c|}{ Preference } & \multicolumn{3}{|c|}{ Normalization } & Average \\
\hline $\mathrm{C} 3$ & Diesel & Electric & $\mathrm{C} 3$ & Diesel & Electric & \\
\hline Diesel & 1 & $1 / 9$ & Diesel & $1 / 10$ & $(1 / 10) /(10 / 9)$ & 0,1000 \\
\hline Electric & 9 & 1 & Electric & $9 / 10$ & $1 /(10 / 9)$ & 0,9000 \\
\hline$\Sigma$ & 10 & $10 / 9$ & $\Sigma$ & 1 & 1 & \\
\hline
\end{tabular}


ISAHP Article: A Style Guide for Individual Papers To Be Submitted to the International Symposium of the Analytic Hierarchy Process 2020, Web Conference.

\begin{tabular}{ccccccc}
\multicolumn{3}{c}{ Preference } & \multicolumn{3}{c}{ Normalization } & Average \\
\hline C4 & Diesel & Electric & C4 & Diesel & Electric & \\
Diesel & 1 & 3 & Diesel & $1 /(4 / 3)$ & $3 / 4$ & 0,7500 \\
Electric & $1 / 3$ & 1 & Electric & $(1 / 3) /(4 / 3)$ & $1 / 4$ & 0,2500 \\
$\Sigma$ & $4 / 3$ & 4 & $\Sigma$ & 1 & 1 & \\
\hline
\end{tabular}

Table 3 shows the multiplication between the preference matrix with the mean of the criteria.

Table 3 - Final result.

\begin{tabular}{|c|c|c|c|c|c|c|c|c|c|}
\hline \multicolumn{5}{|c|}{ Preference matrix } & \multicolumn{4}{|c|}{ Criteria Averages } & \multirow[t]{2}{*}{ Result } \\
\hline & $\mathrm{C} 1$ & $\mathrm{C} 2$ & $\mathrm{C} 3$ & $\mathrm{C} 4$ & $\mathrm{C} 1$ & $\mathrm{C} 2$ & $\mathrm{C} 3$ & $\mathrm{C} 4$ & \\
\hline Diesel & 0,8333 & 0,1666 & 0,1000 & 0,7500 & 0,11565476 & 0,26946429 & 0,57625 & 0,03863095 & 0,204065 \\
\hline Electric & 0,1666 & 0,8333 & 0,9000 & 0,2500 & & & & & 0,795935 \\
\hline
\end{tabular}

As observed in the table above, after analyzing the criteria between the alternatives and considering the weight assigned to each one, a favorable result is observed for the use of electric propulsion in relation to diesel.

\section{Limitations}

The main limitation of this study lies in that our analysis was conducted using only data made available by the Brazilian Navy, because the military ships present some of their data as confidential.

\section{Conclusions}

The objective of this paper was achieved. Through the analysis of the data of installed capacity, energy consumption and gross mass of the systems, it was verified the technical feasibility of the adoption of electric propulsion in new passenger transport vessels in place of conventional diesel. Although its cost of implementation is high, the operating expenses of the electrical system are about four times lower, justifying its economic viability.

The application of the AHP method proved to be efficient, resulting in a ranking of the options, hierarchizing them in a clear and coherent manner according to the criteria and weights established by the decision-maker, thus providing a technical and scientific basis in the formation of his choice. It was found that the preference for the adoption of the electric propulsion system in the analyzed vessels is about four times higher than conventional diesel, where the criteria of socio-environmental aspect and operational cost contributed more significantly to the result.

\section{Key References}

Mello, Luiz; Flag, Renata; Son, Joseph; Competitiveness Analysis of National Shipyards Manufacturers of Offshore Vessels Through Multiple Case Study. Electronic Scientific Journal of Production Engineering,v.11, n. 2, p. 369-398, Apr./Jun., 2011

Saaty, T. L. The Analytic Hierarchy Process. Mcgraw-Hill, New York, 1980. 
ISAHP Article: A Style Guide for Individual Papers To Be Submitted to the International Symposium of the Analytic Hierarchy Process 2020, Web Conference.

Symington, William P. et al. Emerging technologies in marine electric propulsion. Proceedings of the Institution of Mechanical Engineers, Part M: Journal of Engineering for the Maritime Environment,v. 230, n. 1, p. 187-198, 2016. 